\title{
The Effect of Organization Culture, Team Work, and Professionalism to Organizational Citizenship Behavior of Teachers at Madrasah Aliyah Negeri in Surakarta Central Java
}

\author{
Slamet Budiyono $^{1^{*}} \quad$ Thamrin Abdullah $^{2} \quad$ Suryadi $^{2}$ \\ 1.School of Management, University State of Jakarta, Indonesia \\ 2.Lecture School of Management, University State of Jakarta, Indonesia
}

\begin{abstract}
The objective of this research was to studies the effect of organization culture, team work, and professionalism to organization behavior citizenship of teacher's Madrasah Aliyah Negeri in Surakarta Central Java. The research was conducted by using survey method with path analysis applied on testing hypothesis. The target population size of this research is 579 of teachers. Research samples selected as much as 237 teachers using simple random sampling technique. Based on this research of data obtained the following conclusions: (1) the organization culture has positive direct effect to organization behavior citizenship of teacher's, (2) the team work as positive direct effect to organization behavior citizenship of teacher's, (3) professionalism has positive direct effect to organization behavior citizenship of teacher's, (4) the organization culture has positive direct effect to professionalism,(5) team work have positive direct effect to professionalism. The conclusion is that the teacher's organization behavior citizenship is effected by the organization culture, team work, and teacher's professionalism. Keywords: Organization Behavior Citizenship, Team work, Professionalism and Organization Culture
\end{abstract} DOI: $10.7176 / \mathrm{JEP} / 10-29-12$

Publication date:October $31^{\text {st }} 2019$

\section{Introduction}

Successful schools need employees who will do more than just their formal tasks and are willing to deliver performance that exceeds expectations. Among the various resources owned by the company, human resources occupy a strategic position among other resources. Without human resources, other resources owned by the organization cannot be utilized let alone to become a product. A good school, in its development must focus on human resources in order to carry out its functions optimally, especially in the face of environmental changes that occur, so that the company can still maintain its superiority and survive in the midst of strong competition at the moment. The quality of human resources in the school can be seen not only from how much the teachers, administrative staff are able to contribute and able to complete all their tasks well, but can be seen how much they have their own initiative in completing other work outside of the job description. In improving the quality of human life many of the problems encountered are very complex problems. Many factors must be considered because their relationship with human life cannot be ignored. But it is clearly realized that education is one of the factors that can improve the quality of human resources of a nation. Education is a very important field for human life because education can encourage improvement in human quality in the form of increased competence.

In the education unit, the position of the teacher has a very strategic role. The teacher becomes one of the determinants of all activities in the school. A teacher has duties and responsibilities towards the ongoing educational process. The low quality of education can cause a decrease in the quality of human resources. OCB is something that must be owned by a teacher. Teachers who have high competence are needed to build quality schools because in the implementation of education in schools need to understand the educational process in schools and carry out their duties properly, so that the process of organizing education in schools can run according and in line with efforts to achieve educational goals effectively and efficient.

Organizational Citizenship Behavior (OCB) can be interpreted as individual contributions that exceed the demands of roles in the workplace. OCB is very necessary because it can improve organizational effectiveness, because OCB is able to influence social aspects in the organization, such as teamwork, communication and other interpersonal skills. A teacher has a very important role for the advancement of education. As stated in the duties and responsibilities of teachers has been regulated in Law RI No. 14 of 2005 concerning teachers and lecturers, in article 1 said that: the teacher is a professional educator with the main task of educating, teaching, guiding, directing, training, evaluating, and evaluating students in secondary education. This law has outlined the main tasks of each teacher, becoming a basic reference for every teacher in carrying out their duties.

Teachers carry out the main tasks and functions that are multi-role that is as an educator, instructor, and trainer. Educators as the development of students, instructors as knowledge or intellectual brain teasers and trainers as the development of students' skills. So it can be concluded that teacher performance is the behavior or activity of a teacher in carrying out their duties and responsibilities in achieving school goals. One of the behaviors in this case is OCB behavior. 
OCB behavior can be done anywhere, does not have to wait in the condition of a large organization or company. OCB can simplify its meaning as working without seeing the benefits in terms of material and nonmaterial after helping colleagues. OCB behavior not only has a good effect on an employee itself but OCB will have a good impact on the organization. If the organization has OCB behavior, it is certain that the organization's performance will also be better, compared to the performance of other organizations that do not have OCB behavior. To create organizational performance that is above average, all employees must be aware of OCB behavior like this.

Less optimal OCB of teachers will have an impact on the quality of education, because without coupled with high OCB behavior, efforts to reform education will not produce optimal results. MAN supervisors in the former Surakarta Residency, stated that OCB teacher behavior still needed to be improved so that the success of the school / madrasah could be more optimal. He also added that OCB teacher behavior is very important for the advancement of education. There are still many teachers who work that only applies a minimum service standard, but there are not many teachers who work beyond what is expected. Similarly, in terms of the desire of the teachers to help ease the burden and other teacher's tasks, it has not been seen yet.

The same thing was explained by the head of the Madrasah education office of the Central Java Ministry of Religion's Regional Office, stating that it is very important that citizenship behavior in the school environment needs to be improved. Caring with fellow teachers is the initial capital to be able to work together in a school to achieve school goals. Internal factors include lack of knowledge about the task, inadequate educational background, lack of experience, lack of motivation for achievement and weak discipline. While external factors that cause low OCB teacher behavior are a less supportive work environment, supervision or supervision from superiors is rarely implemented, minimal facilities and infrastructure as well as inadequate rewards.

The importance of OCB's behavior in an organization is something that needs to be considered by every leader of the organization. This was stated by Tamunomiebi and Onah (2019), in their research journal stating "organizational citizenship behavior is a related construct within the fields of Organizational Behavior (OB). Organizational Behavior is a field of study that investigates the impact that individuals, groups, and structures have on behavior within the organization, for the purpose of applying such knowledge towards improving an organization's effectiveness. Organizational behavior is the systematic study of behavior and attitudes of both individuals and groups within organizations. A collection of volunteer and non-obligatory behavior that is not defined in the official employee job descriptions but contributes to effective improvement of tasks and roles in an organization. Likewise Mariela (2013), also stated the importance of OCB behavior instilled in each employee, "the affective state, the situational factors and the individual differences such as consciousness, agreeability, positive affectivity, self-esteem, need for affiliation, empathy, and field dependencies were identified as determinants of the OCB. Workplace attachment constitutes a better predictor of organizational citizenship behavior as compared to the organizational commitment.

Based on this problem, the researcher is interested in researching more about the influence of organizational culture, teamwork, and professionalism on organizational citizenship behavior of MAN teachers in the former residency of Surakarta, Central Java. This study looks at what variables are causing OCB MAN teachers in Surakarta. Variables that can be related to OCB problems are organizational culture, teamwork, professionalism, and organizational commitment, organizational commitment, trust and several other factors thought to influence Organizational Citizenship Behavior. The researcher will choose three variables that can influence Organizational Citizenship Behavior for MAN teachers in Surakarta, namely organizational culture, teamwork, and professionalism. Through a literature review, researchers collect various concepts for all variables to be studied from various sources put forward by a number of experts as reference material.

\section{Organizational Citizenship Behavior}

Organizational citizenship behavior is behavior that is carried out without coercion. The results of this behavior always have a positive impact on the progress of the organization, assistance to others who are not unexpected, meaning that organizational citizenship behavior promotes mutual help among employees, and choice, means employees can choose to take action or not. OCB involves a number of behaviors, including helping others, volunteering for extra tasks, obeying rules and procedures at work. This behavior illustrates the added value of employees which is a form of prosocial behavior, namely positive, constructive and meaningful social behavior that helps. OCB has attracted the interest of experts to investigate it further, one of which is to find out the reasons or motives of employees to do so.

Thus the Organizational Citizenship Behavior that organizational citizenship behavior is an action taken by an individual outside of his formal duties voluntarily with indicators of being helpful, good relations with colleagues, tolerance, having more contributions, responsible for improving work quality.

In particular, employees sometimes demonstrate organization citizenship behaviors, which are dicretionary actions above and beyond the call of duty that promote the organization's success. Organizational citizenship is often marked by its spontaneity, its voluntary nature, its constructive impact on result, its unexpected helpfulnes 
to others, and the fact that it is optional, (Newstorm, 2007). The second category of citizenship behavior is organizational citizenship behavior. These behaviors benefit the larger organization by supporting and defending the company, working to improve its operations, and being especially loyal to it, (Colquitt, 2011). OCB as "individual behavior that is discretionary, not directly or explicity recognized by the formal reward system, and that in the aggregate promotes the effective functioning of the organization. The personality foundation for these OCBs reflects the employee's predispositional traits to be cooperative, helpful, caring, and conscientious, (Luthans, 2011). High OCB will be achieved if the rules that have been established by an organization can be done well, and effect by:

\subsection{Organization Culture}

An organization is a system that influences one another, if one of the sub-systems is damaged, it will affect other sub-systems. The system can run properly if the individuals in it are obliged to manage it, which means that as long as members or individuals still like and carry out the responsibilities as they should then the organization will run well. Human resource management is a means to improve human quality, by improving human resources, also improving the performance and results of the organization, so as to realize employees who have discipline and high performance so that it also requires a large role from the leadership of the organization. In improving employee performance, it is necessary to analyze the factors that influence it by taking into account the needs of employees, including the formation of a good and coordinated organizational culture. Organizational culture is the rules, values, and norms agreed upon by all members of the organization as a basis for carrying out activities and achieving organizational goals with indicators: adherence to rules, agreed norms, dominant values, agreed rules, stability in the organization, and appreciation of achievement. Organizational cukture is a system of shared values, expectations, and behaviors that guide member's attitudes and behaviors establishes the context for everything people in an organization do. Strong ethical cultures are created when leaders live ethically every day and clearly communicate the firm's expectations to prospective and new employees, (Philips, 2012). Organizational culture may be referred to as the common set of assumptions, beliefs, and values that has developed within the organization to cope with the external and internal environment and that is passed on to new members to guide their actions within these environments, (David , 2005). Organizational culture is a complex and deep aspect of organizations that can strongly affect organization members. Organizational culture includes the values, norms, rites, rituals, ceremonies, heroes, and scoundrels in the organization's history. It defines the content of what a new employee needs to learn to become an accepted organization member, (Joseph E. Champoux, 2006).

\subsection{Team Work}

In an organization, the way the team works determines the work output produced. Individual contributions can produce brilliant ideas and produce intuitive decisions. Nevertheless, the ideas and decisions must be corrected and applied in a team context. A team must have a clear shared goal, which is something that everyone understands and believes. A common goal can be a sales target, developing a new process, or managing a group of business units. Whatever the goal, the effort to achieve that goal is the reason for the existence of a team. Organizations generally believe that to achieve excellence must strive for the highest individual performance, because basically individual performance affects the performance of a team or work group and ultimately affects overall organizational performance.

Teamwork is a process in which a group of individuals work together, in a coordinated way to achieve certain goals that have been set, with indicators: coordination, interpersonal activities, responsibilities, support between individuals, and cooperation. Teams are a central aspect of organizational life, and the ability to manage them is a vital component of manager and organizational success. Teamwork provides benefits or companies wouldn't continue to use this structural mechanism. Organizational are by their very nature made up of various individuals and group that have to work together and coordinate their activities to accomplish objectives, (Daft, 2012). Teamwork is the process of people working together to accomplish these goals, (Schermerhorn, 2012). Teams and teamwork are currently being championed as a way replacing inflexible, dehumanized, bureaucratic mechanism with more humanistic, involving, cultural ideological methods of productive activity, (Shani, 2007).

\subsection{Proffesionalism}

Attitude is a tendency for someone to behave. Attitudes toward the profession can be regarded as an initial reflection of the quality of a teacher that will relate to the quality of education as a whole, bearing in mind that attitudes originate from within a person in judging something outside of himself or others. Attitude is also the basis of a person before taking an action. A positive teacher's attitude towards his profession is the desire of every member of the community because with this positive attitude the teacher is expected to always be able to increase his capacity and competence as an educator so that he will become a professional teacher who can improve the quality of education for students. Conversely, negative attitudes of teachers to their profession are likely to worsen the condition, quality, capacity, and competence of these teachers, which in turn will worsen the overall quality of 
education. How is it possible that someone will be able to work with maximum quality if the person concerned does not like the job. Conversely someone who solely because of love like hobbies continues to work will be able to create extraordinary masterpieces. That is caused by the very close relationship between attitudeand behavior. Professionalism is an ideal psychological condition that exists in a person including values, thoughts, beliefs, perceptions, hopes, and feelings with indicators: honest in behaving, responsible for work, big-hearted, confident, and initiative in working. Professionalism is at once an embodiment of societal ideals and an in-your-face representation of who matters and who doesn't, (Cheney, 2010). Attitude is the sum total of your beliefs, assumptions, expectations, and values, (McPherson, 2008). Attitude as a state of emotional being or mindset. More clearly, our attitude is the emotional response we have toward situations and people. It is the mental tone we emit. It is an outward expression of our thoughts and feelings, Glenn, 2010). By the term attitudes, we mean tendencies to evaluate an object positively or negatively. People can possess attitudes toward any concrete object or abstract issue in their environment, (Delamater, 2006).

There is an effect of Organization Culture on OCB, "Organizational culture within a given frame of work can shape OCB behavior among employees. This reflected that the higher the organizational culture will shape the OCB behavior will better. The results of the study showed that organizational culture had a positive effect on OCB, found that organizational culture had a significant effect on OCB", (Catherin, et al, 2008).

The effect of group Team Work on OCB as follows: "team as a small number of people with complementary skills, who are committed to common performance standards, and agree on the approach for mutual responsibility, and indicate that teamwork is a group of human beings that they have high performance, when its members along with the spirit that enables them to achieve the group goals in the workplace with confidence and cooperation, and reduces the workload for everyone which enables them to exchange ideas and assignments, (Mohammed, 2017). The effect of proffesionalism on OCB, "arguments that support attitude towards work cause performance usually refer to the functions of attitudes as guidelines and facilitators of behavior or refer to functions of attitude as the energizing and facilitative effects of positive affect (as one component of satisfaction) the workplace; or refer to the functions of attitudes as the motivational effects of the personal importance or identification with the job or organization", (Sivasakthi, 2015).

\section{Methodology}

This quantitative research uses survey method through analysis approach. Before being used in research, an instrument test was conducted to test the validation and reliability of each item so that it could be used in research. The study was conducted on 237 MAN teachers in Surakarta. From the number of teachers as many as 579 teachers were taken using the Slovin formula. A sample of 237 teachers were obtained by a simple random method from the population and spread to all MANs in Surakarta.

The data in this study were concluded using a questionnaire-shaped instrument that included the Organizational Citizenship Behavior questionnaire, organizational culture, and professionalism, which had gone through the stages of empirical validation through instrument trials. Furthermore, the reliability calculation is done on the valid instrument items that indicate the appropriateness of the instrument to be used in research. The results of the validation test and instrument reliability calculation are as follows: (1) Organizational Citizenship Behavior questionnaire, validation $=91.43 \%$, reliability $=0.958,(2)$ organizational culture questionnaire, validation $=$ $85.71 \%$, reliability $=0.955$, (3) teamwork questionnaire, validation $=88.57 \%$, reliability $=0.930$, (4) professionalism questionnaire, validation $=91.43 \%$, reliability $=0.941$. So it was concluded that all valid instrument items are reliable instruments.

Research data analysis techniques were analyzed using descriptive analysis and inferential analysis with a path analysis approach. Descriptive analysis is done by calculating the average value, median, mode, variance, and standard deviation. The data characters of each variable are displayed in the frequency distribution and histogram tables. Inferential analysis is preceded by analysis requirements test, consisting of estimated error normality test, significance test, and linearity test.

\section{Result and Discussion}

Data analysis to test the research hypothesis is carried out by statistical analysis or path analysis. Before testing the hypothesis first, the analysis of the requirements analysis is carried out which includes the following: (1) testing the estimated normality error, and (2) the significance test and regression linearity.

Test the estimated normality error using the liliefors test. The test criteria is if $\mathrm{L}_{\text {counts }}<\mathrm{L}_{\text {table }}$ at $\alpha=0.05$, then the regression equation is normally distributed. Based on the calculation of the $\mathrm{Y}$ error estimation normality test for $\mathrm{X}_{1}, \mathrm{Y}$ for $\mathrm{X}_{2}, \mathrm{Y}$ for $\mathrm{X}_{3}, \mathrm{X}_{3}$ for $\mathrm{X}_{1}, \mathrm{X}_{3}$ for $\mathrm{X}_{2}$, all of them indicate that $\mathrm{L}_{\text {counts }}<\mathrm{L}_{\text {table }}$ so that all regression equations are normally distributed.

For the significance test carried out by ANAVA calculation with the test criteria is if $F_{\text {count }}>F_{\text {table }}$ at $\alpha=0.01$ then the regression coefficient between variables is significant. Based on the results of the calculation of the significance test $\mathrm{Y}$ for $\mathrm{X}_{1}, \mathrm{Y}$ for $\mathrm{X}_{2}, \mathrm{Y}$ for $\mathrm{X}_{3}, \mathrm{X}_{3}$ for $\mathrm{X}_{1}$, and $\mathrm{X}_{3}$ for $\mathrm{X}_{2}$, all of them indicate that $\mathrm{F}_{\text {count }}>\mathrm{F}_{\text {table }}$, the 
regression coefficient between all variables is very significant. To test linearity of simple regression equations with criteria that if $F_{\text {count }}<F_{\text {table }}$ then the relationship between variables is linear. Based on the calculation of the $Y$ linearity test for $\mathrm{X}_{1}, \mathrm{Y}$ for $\mathrm{X}_{2}, \mathrm{Y}$ for $\mathrm{X}_{3}, \mathrm{X}_{3}$ for $\mathrm{X}_{1}, \mathrm{X}_{3}$ for $\mathrm{X}_{2}$, all of them show that $\mathrm{F}_{\text {counts }}<\mathrm{F}_{\text {table, so all relationships }}$ between variables are linear.

After testing the estimated normality error, significance test and regression linearity, path analysis is conducted to test the research hypothesis. The following table describes the results of the calculation and path coefficient testing with $t_{\text {table }}=2.334$ for $\alpha=0.01$ with the criteria if $t_{\text {count }}>$ from $t_{\text {table }}$ then the path coefficient test results show that the path is very good and can explain the influence between variables.

Tabel 1. Results and Path Coefficient Testing

\begin{tabular}{cccc}
\hline Jalur & Koefisien Korelasi & Koefisien Jalur & $\mathrm{t}_{\text {hitung }}$ \\
\hline $\mathrm{X}_{1}$ On Y & $\mathrm{r}_{1 \mathrm{y}}=0,546$ & $\mathrm{p}_{\mathrm{y} 1}=0,355$ & 6,863 \\
\hline $\mathrm{X}_{2}$ On Y & $\mathrm{r}_{2 \mathrm{y}}=0,588$ & $\mathrm{p}_{\mathrm{y} 2}=0,354$ & 5,589 \\
\hline $\mathrm{X}_{3}$ On Y & $\mathrm{r}_{3 \mathrm{y}}=0,517$ & $\mathrm{p}_{\mathrm{y} 3}=0,155$ & 2,451 \\
\hline $\mathrm{X}_{1}$ On $\mathrm{X}_{3}$ & $\mathrm{r}_{13}=0,371$ & $\mathrm{p}_{31}=0,146$ & 2,780 \\
\hline $\mathrm{X}_{2}$ On $\mathrm{X}_{3}$ & $\mathrm{r}_{23}=0,651$ & $\mathrm{p}_{32}=0,596$ & 11,320 \\
\hline
\end{tabular}

Thus it can be concluded the path between organizational culture variables on Organizational Citizenship Behavior, team work on Organizational Citizenship Behavior, and professionalism on Organizational Citizenship Behavior, organizational culture on professionalism, and teamwork on professionalism, the path coefficient is significant because the tcount $>$ ttable. The path coefficient test results in this study indicate that the path is very well shaped and can explain the influence of organizational culture, teamwork, and professionalism on Organizational Citizenship Behavior of MAN teachers in Surakarta. So that it can explain the influence of exogenous variables with endogenous variables analyzed. The results of the study mean that generally in MAN teachers in Surakarta there are five positive direct influences: (1) organizational culture on Organizational Citizenship Behavior, (2) teamwork on Organizational Citizenship Behavior, (3) professionalism on Organizational Citizenship Behavior, (4) organizational culture towards professionalism, (5) teamwork towards professionalism.. In detail the discussion of the results of the analysis and testing of the research hypothesis is described as follows:

\section{a. Effect of Organization culture on Organization Citizenship Behavior}

To prove that organizational culture has a direct positive effect on Organizational Citizenship Behavior, the statistical hypothesis is: $\mathrm{H} 0: \beta \mathrm{y}_{1} \leq 0, \mathrm{H1}: \beta \mathrm{y}_{1}>0$. The results of the calculation of the influence of work organization culture on Organizational Citizenship Behavior, obtained a path coefficient of 0.355 and a calculated value of the path coefficient this is $6.863, \mathrm{t}_{\text {count }}(6.863)>\mathrm{t}_{\text {table }}(2.334)$ at $\alpha=0.01$, then $\mathrm{H} 0$ is rejected. It can be concluded that there is a positive direct effect of organizational culture on Organizational Citizenship Behavior. That is, an increase in organizational culture will result in an increase in Organizational Citizenship Behavior. The results showed that organizational culture influences Organizational Citizenship Behavior, it can be interpreted that the organizational culture owned by teachers, causes an increase in Organizational Citizenship Behavior for MAN teachers in Surakarta. Based on this empirical evidence, the findings show that organizational culture is one of the variables that directly influences Organizational Citizenship Behavior. Organizational culture will affect the increase in Organizational Citizenship Behavior for teachers.

\section{b. $\quad$ Effect of Team Work on Organization Citizenship Behavior}

To prove that teamwork has a direct positive effect on Organizational Citizenship Behavior, the statistical hypothesis is: $\mathrm{H} 0: \beta y_{2} \leq 0, \mathrm{H} 1: \beta y_{2}>0$. The results of the calculation of the effect of teamwork on Organizational Citizenship Behavior, obtained a path coefficient of 0.354 and a calculated value of the path coefficient of this path equal to $5.589, \mathrm{t}_{\text {count }}(5.589)>\mathrm{t}_{\text {table }}(2.334)$ at $\alpha=0.01$, then $\mathrm{H} 0$ is rejected. Thus it was concluded that there was a positive direct effect of teamwork on Organizational Citizenship Behavior. The results showed that teamwork influenced Organizational Citizenship Behavior, which means that good teamwork would lead to an increase in Organizational Citizenship Behavior for MAN teachers in Surakarta. Based on this empirical evidence, the findings show teamwork is one of the variables that directly influences the Organizational Citizenship Behavior variable. Good teamwork will affect the increase in Organizational Citizenship Behavior for teachers.

\section{c. Effect of Professionalism on Organization Citizenship Behavior}

To prove that professionalism has a direct positive effect on Organizational Citizenship Behavior, the statistical hypothesis is: $\mathrm{H} 0: \beta y_{3} \leq 0, \mathrm{H} 1: \beta y_{3}>0$. The results of the calculation of the effect of professionalism on Organizational Citizenship Behavior, obtained a path coefficient of 0.155 and the calculated value of the path coefficient of $2.451, \mathrm{t}_{\text {count }}(2.451)>\mathrm{t}_{\text {table }}(2.334)$ at $\alpha=0.01$, then $\mathrm{H} 0$ is rejected. Thus it was concluded that there was a positive direct effect of professionalism on Organizational Citizenship Behavior. The results show that professionalism influences Organizational Citizenship Behavior, which means that an increase in professionalism is perceived by teachers will lead to an increase in Organizational Citizenship Behavior for MAN teachers in Surakarta. Based on this empirical evidence, it is said that this finding shows professionalism is one of the variables that directly influences the Organizational Citizenship Behavior variable. High professionalism will 
affect the increase in Organizational Citizenship Behavior for teachers.

\section{d. Effect of Organization Culture on Professionalism}

To prove that organizational culture has a direct positive effect on professionalism, the statistical hypotheses are: $\mathrm{H} 0: \beta_{31} \leq 0, \mathrm{H1}: \beta_{31}>0$. The results of the calculation of the influence of organizational culture on professionalism, obtained a path coefficient of 0.146 and the $t$-value of this path coefficient of $2.780, t_{\text {count }}(2,780)>$ $t_{\text {table }}(2,342)$ at $\alpha=0.01$, then $\mathrm{H} 0$ is rejected. Thus it was concluded that there was a positive direct effect of organizational culture on professionalism. The right organizational culture will increase the professionalism of the teacher. The results showed that organizational culture influences professionalism, it can be interpreted that a good organizational culture owned by teachers, will lead to an increase in the professionalism of MAN teachers in Surakarta. Based on this empirical evidence, the findings show that organizational culture is one of the variables that directly influences the professionalism variable.

\section{e. $\quad$ Effect of Team Work on Professionalism}

To prove teamwork has a direct positive effect on professionalism, the statistical hypotheses are: $\mathrm{H} 0$ : $\beta_{32} \leq$ $0, \mathrm{H} 1: \beta_{32}>0$. The results of the calculation of the influence of teamwork on professionalism, obtained a path coefficient of 0.596 and the $t$-value of this path coefficient of $11.320, t_{\text {count }}(11,320)>t_{\text {table }}(2,342)$ at $\alpha=0.01$, then $\mathrm{H} 0$ is rejected. It was concluded that there was a positive direct effect of teamwork on professionalism. The results showed that teamwork influenced professionalism, which meant that good teamwork would cause the professionalism of MAN teachers in Surakarta to increase. Based on this empirical evidence, the findings show teamwork is one of the variables that directly influences the professionalism variable. Good teamwork will affect the professionalism of the teacher.

Table 2. Recapitulation of the Result of Hypothesis Test

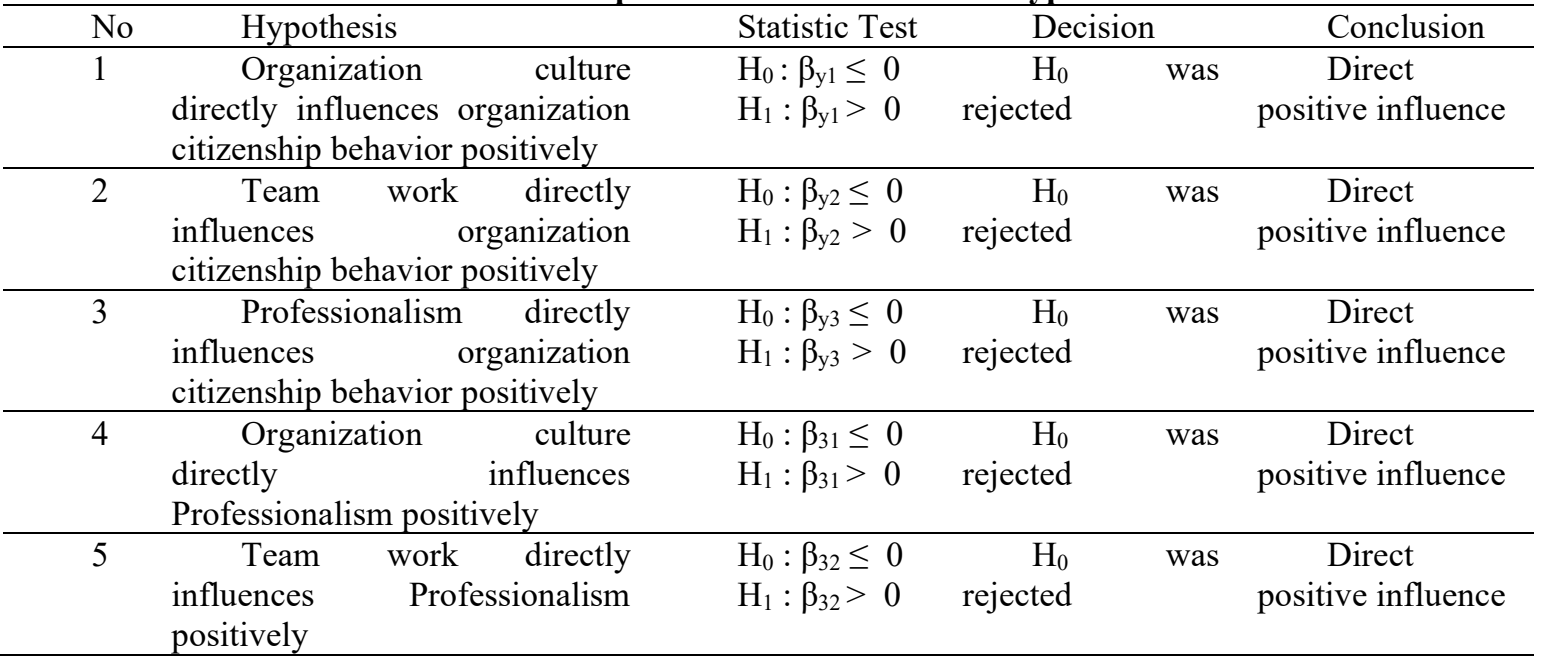

\section{Conclusion}

Based on the results of calculations and testing of hypotheses and discussion of the results of research that has been stated, through research conducted on MAN teachers in Surakarta produced the following research conclusions: (1) Organizational culture has a direct positive effect on Organizational Citizenship Behavior of teachers, with indicators of compliance with rules having a level the most significant influence on Organizational Citizenship Behavior. This means that if organizational culture is improved, it will have an effect on increasing teacher organizational Citizenship Behavior. It is expected that a teacher has the character to help fellow colleagues both within the school environment and outside the school environment. The nature to be willing to help can improve the Organizational Citizenship Behavior of MAN teachers in Surakarta; (2) Teamwork has a direct positive effect on teacher's Organizational Citizenship Behavior, with indicators of obedience to rules giving the most significant influence on Organizational Citizenship Behavior. This means that if teamwork is improved it has an effect on increasing teacher organizational citizenship behavior. And it is expected that teachers who are able to work obediently to the rules in force. This will be able to improve the Organizational Citizenship Behavior of MAN teachers in Surakarta; (3) Professionalism has a direct negative effect on the Organizational Citizenship Behavior of teachers, with indicators of interpersonal support giving the most significant influence on Organizational Citizenship Behavior. This means that if there is an increase in teacher professionalism, it can have an influence on the increase in Organizational Citizenship Behavior for teachers. It is expected that teachers support each other in carrying out their work, for example in solving problems they face need support from other co-workers. Thus increasing teacher professionalism attitudes will improve Organizational Citizenship Behavior for MAN teachers in Surakarta; (4) Organizational culture has a direct positive effect on teacher professionalism, with agreed rule indicators giving the most significant positive influence on professionalism. This means that if 
organizational culture is improved it can have an influence on increasing teacher professionalism. And it is expected that the application of applicable rules, as well as being done well, will lead to an increase in the professionalism of MAN teachers in Surakarta; (5) Teamwork has a direct positive effect on teacher professionalism, with indicators of responsibility providing the most significant positive influence on professionalism. This means that if teamwork is improved it can have an influence on increasing teacher professionalism. It is expected that teachers who are responsible for carrying out their duties will lead to increased professionalism of MAN teachers in Surakarta. Based on the above research findings, it can be stated that Organizational Citizenship Behavior can be influenced by variables of organizational culture, teamwork, and professionalism. However, other variables still need to be considered in further research relating to the Organizational Citizenship Behavior variable. Based on the conclusion of this research, it can be concluded that improving teacher organizational behavior can be done by improving organizational culture, teamwork, and increasing professionalism in teachers.

\section{Acknowledgement}

By saying praise and gratitude to the presence of God Almighty, because of all His mercy and grace, the author can complete the writing of this dissertation. As one of the requirements This dissertation entitled "The Effect of Organization Culture, Team Work, and Proffesionalism to OCB of Teachers at MAN Surakarta" is submitted as the final requirement to obtain the title of Doctor of Education Management from the Postgraduate Program of the Jakarta State University.

In arranging this disertation, a lot of people have provided motivation, advice, and support for the researcher. In this valuable chance, the researcher intended to express his gratitude and appreciation to all of them. First, the researcher's deepest appreciation goes to all my falily for the endless love, pray, and support and for the phone call every week in order to remind me to keep going and never giving up.

Deep gratitude, the authors give to all parties, both directly and indirectly, who have contributed to the writing of this dissertation. The author realizes that this dissertation is composed of assistance and guidance from various parties, for which the author expresses his deepest gratitude and appreciation to the honorable, Prof. Dr. Intan Ahmad, Ph.D As Chancellor at the University of Jakarta, Prof. Dr. Ilza Mayuni, MA, as postgraduate director, and Dr. Suryadi as education management program coordinator. Prof. Dr. Thamrin Abdullah, as a promoter who always provides motivation in completing this dissertation. Dr. Suryadi as Co Promoter who always gives enthusiasm, motivation and directs the writer so that this dissertation can be completed. Lecturer in the Education Management Postgraduate Program at the Jakarta State University who has shared knowledge with the author.

Finally, I would like to thank everybody who was important to the successful realization of this undergraduate thesis. This undergraduate disertation is far from perfect, but it is expected that it will be useful not only for the researcher, but also for the readers. For this reason, constructive thoughtfull suggestion and critics are welcomed.

\section{References}

Colquitt at al, Organizational Behavior, Improving Performance and Commitment in the Workplace, Second Edition, New York : McGraw-Hill: 2011

David J. Fritzsche, Business Ethics: A Global \& Managerial Perspective, New York: McGaw-Hill, 2005

Gibson at al, Organizations, Behavior Structure Processes, New York, McGraw-Hill, 2006

Griffin Moorhead . Organizational Behavior, Managing People and Organizations, New York: Houghton Mifflin Company, 2007

Ivancevich, Organizational Behavior and Management. Eighth Edition, New York: McGraw Hill Companies, 2008

Jennifer M. George, Gareth R.Jones, Understanding and Managing Organizatinal Behavior, New Jersey: Pearson, 2012

Jhon.R.Schermerhorn et al, Organizational Behavior, United States of America: Jhon Wiley \& Sons, 2010

Kreiner, Kinicki, Organization Behavior, Ninth Edition, New York, McGraw-Hill Irwin, 2010

Luthans, Fred, Organizational Behavior, Elevent Edition, New York: Mc Graw Hill, 2011

Mariela, Organizational Citizenship Behavior, Work Satisfaction an Employee's Personality, Procedia - Social and Behavioral Sciences, 2013

McShane,Von Glinow, Organizational Behavior, New York: McGraw-Hill Irwin, 2008

Phillips, Gully, Organizational Behavior, Tools For Success (USA: South-Western Cengage Learning, 2012

Richard L, Daft, New Era of Management, Canada: South-Western Cengange learning, 2010

Shani,A.B at al, Behavior In Organizations, An Experience Approach, Ninth Edition, New York, McGraw-Hill, 2009

Slocum, Don Hellriegel, Fundamentals of Organizational Behavior, USA: Thomson Shout Western, 2007

Stephen P. Robbins, Organizational Behavior, New Jersey: Prentice-Hall International; 2009

Steve M. Jex, Organizational Psychology: A Scientist-Practitioner Approach, New York: John Wiley \& Sons, 
Tamunomeibi, Onah, Organizational Citizenship Behavior; A Critical Review of Its Development In a Diversity Driven Workplace, The Startegic Journal of Busines \& Change Management, 2019 